IJMS 18 (2), 67-82 (2011)

\title{
ACQUIRING INTERNATIONAL KNOWLEDGE AND EXPERIENCE: INTERNATIONALIZATION OF SMALL AND MEDIUM ENTERPRISES (SMEs)
}

\author{
SHANKAR CHELLIAH \\ School of Management \\ Universiti Sains Malaysia \\ MOHAMED SULAIMAN \\ Kulliyyah of Economic and Management Sciences \\ International Islamic University Malaysia
}

\begin{abstract}
Purpose - This paper intends to understand the importance of acquiring international knowledge and experience and its relationship in the internationalization of Small and Medium Enterprises (SMEs) in the Malaysian context. Within this scope, this study sets out to further the discussion by comparing the global orientation of SMEs in Malaysia with their different levels of firm size. In a nutshell, the study further understands the moderating effect of firm size between the relationship of international knowledge and experience, and internationalization of SMEs.
\end{abstract}

Design/Methodology/Approach - The study is based on literature review in the areas of SMEs internationalization, international knowledge and experience, and the firm size. The data was collected using a survey instrument among 300 internationalized enterprises located in the northern region of Malaysia.

Findings - The results suggest that those firms that acquire international knowledge and experience have no significant relationship with firm internationalization. However, when firm size is used as a moderating factor, acquiring international knowledge and experience shows some importance for internationalization of firms. Interestingly, international knowledge and experience are important for relatively smaller firms. In other words, firm size is significant when relatively smaller SMEs acquire international knowledge and experience. It poses some implications for managers and policy makers. 
Originality/Value - This study explores the use of the index of internationalization to measure the internationalization of SMEs in Malaysia.

Keywords: International knowledge and experience, index of internationalization, firm size.

\section{Introduction}

A highly-skilled human capital possessing international knowledge and experience is an undeniable requirement for sustainable economy at the macro level. The predicament is that the higher the liberalization of the industrialization, the higher is the importance for the SMEs to acquire such continuous learning to sustain their competitiveness in the international market. It can be stated that the gains to a country from the internationalization of SMEs can be very substantial as a result of the acquisition of international knowledge and experience.

The importance of international knowledge and experience has received considerable attention in the last few years. Despite this attention, and the creation of knowledge-management departments in many companies, including SMEs, the depth and intensity of that knowledge and experience still has a long way to go. Many have argued that we are in a knowledge economy in which intellectual capital is very crucial and has to be given equal importance as the other factors of production.

In the last two decades, the intensity of research on SMEs has generated some interesting research issues such as international entrepreneurship and international new ventures or global new ventures. These researches reveal that firms which have been described as "born global" or "international new ventures," have a strong international focus from their inception (Bell, McNaughton, Young \& Crick, 2003; Coviello, 2006; Oviatt \& McDougall, 2005). The effort of adopting international perspectives in the short-term and long-term strategies among the SMEs began as early as the 1980s (Tesar \& Moini, 1998).

Further studies by Melia, Boulard, and Peinado (2007) show the importance of entrepreneurial orientation and international commitment in making international ventures successful. International corporate entrepreneurship emerges as a new perspective in the

68 IJMS 18 (2), 67-82 (2011) 
study of firm internationalization. This new perspective is mainly characterized by the extent of emphasis on international knowledge and experience by entrepreneurs. The lack of international entrepreneurship orientation will add on to the list of disadvantages for SMEs that were listed by Aldrich and Auster (1986) for SMEs marching towards internationalization.

\section{Objective of the Study}

Broadly conceived, the criticality of acquiring international knowledge and experience is realized by the SMEs' strategic leaders. The attributes of knowledge and experience become clearer with the conversion of the resources into valuable business opportunities in the international market. For example, the present economic problems in the world need to be well understood by the SMEs before embarking on the global business operation.

In this paper, we aim to study the importance of international knowledge and experience to SME internationalization and how the size of the SMEs moderates that relationship for greater internationalization effort. The contribution of this study is twofold. First, it reveals to policy makers the role and importance of international knowledge and experience and secondly, it attempts to understand the role of size in the adoption of internationalization. Basically, the objective of this study can be outlined as the following:

(1) To understand the relationship between international knowledge and experience and internationalization.

(2) Tounderstand the moderating of firm size between international knowledge and experience and internationalization.

\section{Literature Review and Hypothesis}

\section{Internationalization of Small and Medium Enterprises in Malaysia}

Research interest in the SMEs in Malaysia has witnessed a significant growth over the years. Why has it become more important in the last two decades? Hashim (2000b) acknowledged the growing number of SMEs in Malaysia and its contribution to the economy. MITI expects the SME sector to contribute more in the period of 2000 and 2020. The SMEs are expected to contribute 50 per cent of the gross domestic product (GDP) in 2020 (Hashim, 2000b). They provide a lot of job opportunities to locals and become major players to determine the pricing of the raw materials. They definitely have a lot of impact and effect on Porter's five forces of competitiveness in the industry. 
SMEs in Malaysia vary in sizes and capability. Abdul Talib and Md. Salleh (1997) pointed out some critical evaluation concerning the relationship between firm size and attitudes toward exporting. The results demonstrated that SMEs have a stronger tendency towards exporting activities than large-sized firms. SMEs are also found to be actively exploring market potential in the international arena. In other words, these firms are looking for broader markets for their products. Obviously, all firms in the study believe that exporting is a desirable activity and can contribute significantly to the firm's growth and profit.

Another research by Zulkifli and Jamaluddin (2000) showed that there is a lack of skills and knowledge in organizing effective manufacturing and business strategy development. About $42 \%$ of the SMEs that were interviewed had prioritized quality and cost as their best weapons to compete regionally. The findings indicated that SMEs lacked documented strategies and proper techniques to measure performance. Most of the companies could not plan for more than five years and the long-term strategies, both of which are crucial for internationalization. They commented that SMEs in Malaysia are very far behind compared to SMEs in Asian countries, such as Taiwan, Korea or Singapore, in terms of innovation in design, speed of delivery and, huge choices and customized products for customers.

\section{International Knowledge and Experience}

Do SMEs in Malaysia foster knowledge acquisition, both tacit knowledge and experiential knowledge? Knowledge and intellectual capital have become the two primary bases of core competencies and the key to superior performance. Lubit (2001) explored how companies can best nurture their knowledge resources to create competitive advantage. To provide sustained competitive advantage, one needs knowledge that is difficult for outsiders to copy as well as the ability to rapidly develop new knowledge. He outlined two paths by which companies could use knowledge to create sustained competitive advantage: (a) tacit knowledge is knowledge that other companies find difficult to copy when it spreads internally, and (b) companies can create superior knowledge management capabilities and foster on-going innovation.

Burpitt and Rondinelli's (2000) study on 138 small firms with exporting experience in North Carolina found that firms that strongly value learning from international experience are more likely to continue exporting. Small firms that value the opportunity to

70 IJMS 18 (2), 67-82 (2011) 
develop new skills, technology and organizational capabilities tend to be involved in internationalization even when initial financial returns are disappointing. The resources of knowledge and skills can either be acquired by hiring managers with knowledge and skills in international markets or developed through training and experience.

Bradley (1999) posited that lack of knowledge with respect to foreign markets and operations can be an important determinant to the lack of development of international operations. As a rule, knowledge and learning will be acquired through operating abroad over a period of time. Besides that, Reuber and Fischer (1997) examined the role of the management team's international experience as a mechanism for the internationalization of Canadian SMEs in the software industry. The results showed that internationally experienced management teams are viewed as a resource that influences SMEs to engage in international businesses. They encourage firms to develop foreign strategic partners and delay less in obtaining foreign sales after start-up.

Many researchers agree that wider experience is closely linked to greater success in the organizations. This is shown in the study involving 51 entrepreneurs in SMEs in Kuala Lumpur to ascertain the usefulness of government-supported programmes to nurture SMEs in Malaysia (Abdullah, 1997). The research results showed that owners who are more experienced achieve higher performance in terms of profit, capital and employment. In this study, internal knowledge and experience refer to knowledge and experience about foreign markets with regards to the products manufactured in the firm.

\section{Firm Size}

While it is important to record the phenomenal growth of the Malaysian economy a decade ago, the sustainability of the economy much depends on the growth of the SMEs which can be measured through their growing size year by year. Only a handful of empirical studies have investigated how size has helped SMEs to internationalize, especially in the Malaysian environment.

Reuber and Fischer's (1997) research on SME internationalization resulted in findings that neither firm size nor firm age, directly and significantly, related to internationalization. However, firm size is positively and significantly correlated to the measure of the team's international selling experience which shows that larger SMEs are more likely to have teams with international selling experience.

IJMS 18 (2), 67-82 (2011) 7 
In Canada, examining fourteen thousand manufactures, Calof (1994) examined the direct and indirect effects of firm size on export behaviour by focusing on three dimensions of the export behaviour: their propensity to export, countries they exported to and export attitudes. The results showed that firm size is positively related to all dimensions of export behaviour. Nevertheless, its importance is limited as the degree of variance explained by size is very small. In earlier studies, Cavusgil $(1976,1984)$ found that when firm size is measured by the number of employees, no relationship is found with export behaviour, but a significant relationship exists when size is measured by annual sales.

A firm can be considered small in two different but related ways; in terms of sheer organizational size or in terms of its industry market share. Although size and market share are conceptually different, they are correlated empirically. Firm size has long been considered one of the most significant contingency variables in macro-organizational studies and its relationship with other important constructs, such as structure (Singh, 1986).

The study by Cavusgil and Nevin (1981) showed a positive relationship between firm size and export activity but another study by Cavusgil (1984) illustrated that size does not influence export activity except for small-sized firms. Besides that, Bonaccorsi (1992) studied the relationship between size and export behaviour in 8,810 Italian companies and showed that firm size is positively associated with propensity to export and negatively associated with export intensity. In this study, firm size referred to annual sales turnover of the firm.

Therefore, the following hypotheses will test the relationship between international knowledge and experience, size and internationalization:

H1: International knowledge and experience has a positive relationship with internationalization.

H2: Firm size moderates the relationship between international knowledge and experience, and internationalization.

\section{Research Framework}

Based on the literature review discussed above, the research framework of this study is depicted in Figure 1.0. The independent variable is international knowledge and experience (IKE), the 
moderating variable is firm size (FS) and the dependent variable is internationalization (I). The research framework shows both hypotheses; $\mathrm{H} 1$ and $\mathrm{H} 2$ which will be tested in the following sections.

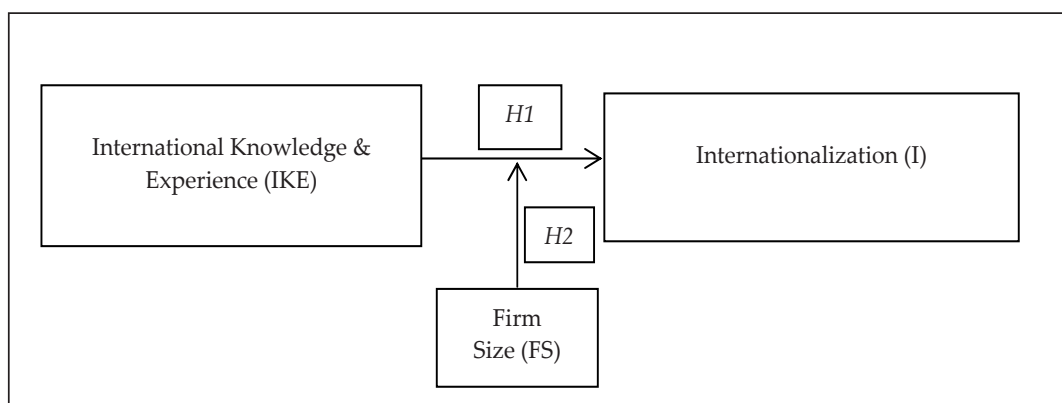

Figure 1.0. The research framework.

\section{Methods}

\section{Sample}

Firms to be contacted were identified from the registered list of companies in the Federation of Manufacturing Companies (FMM) directory and the Perlis Labour Department. FMM was used to locate firms in Pulau Pinang, Kedah and Perak, whereas, the Perlis Labour Department was used to find firms in Perlis since the FMM directory has a limited number of firms from Perlis. The FMM directory was used since it consolidates the list of manufacturing firms and provides easy access through CD ROM which is helpful for sample selection through the stratified random sampling method. The total registered SMEs from both sources were 1,363 who meet the requirements of the SMEs.

This study used SMEs in Perak, Pulau Pinang, Kedah and Perlis as a sampling population. Probability sampling was used as the sampling design. In the probability sampling design, the stratified random sampling process was applied to choose the sample. The sample was from manufacturing companies. Manufacturing companies were considered appropriate for this study for two reasons. First, the manufacturing industry is one of the major contributors to the economy. Secondly, the manufacturing industry is the most vulnerable to globalization.

IJMS 18 (2), 67-82 (2011) 73 
Stratified random sampling, as its name implies, involves a process of stratification or segregation, followed by a random selection of subjects from each stratum. In this study, the population of 1,363 SMEs was segregated based on the combination of criteria such as the number of employees being not more than 150, operating for a minimum of three years, established as of Malaysian origin and have been involved in exporting activities. Based on these criteria, a total of 300 SMEs were selected from the total of 1,363 SMEs. Since only 300 SMEs qualified with the criteria, no random selection was used instead. All the selected 300 SMEs were used as the sample in this study.

\section{Design and Procedure}

The primary data were collected from top executives of SMEs who assumed the role of key informants through a mail questionnaire. The unit of analysis in this study was the individual SME. The respondents (i.e., executives, CEOs and upper-level managers with a strategic responsibility for their firms) were identified on the basis of their job titles and positions within the company. They were assumed to be knowledgeable and familiar with the operations related to the issues under investigation. The questionnaires were sent through post. Regression analysis was used to test the hypothesis.

\section{Measures}

Internationalization is measured as an index. Since some international business researchers have expressed that a multi-dimensional measure of internationalization captures a firm's international orientation more completely than the single-item foreign sales/total sales ratio (George, Wiklund \& Zahra, 2005; Reuber \& Fischer, 1997; Sullivan, 1994), the author has developed an index to measure SMEs' internationalization. Selected internationalization variables were put into this index following a factor analysis which showed that these variables fall into one factor. The index was named the index of internationalization (IOI).

Many studies have used the percentage of sales and profits from international sources as a better way to measure internationalization. Almost all the literature uses these variables to measure internationalization because they reflect instantaneously the amount of export sales and profit from export businesses. Approximately 40 per cent of the SMEs in this study achieved 11-20 per cent of their sales and profit from international sources. Therefore, a relatively higher weightage of 30 each was given for both constructs.

74 IJMS 18 (2), 67-82 (2011) 
Next, the number of countries a firm exports to and the total overseas subsidiaries and joint ventures are given a relatively a smaller weightage of 15 each. Approximately 75 per cent of the SMEs in this study export to less than 10 countries while 60 per cent of the SMEs have less than three subsidiaries or joint ventures. Therefore, it is appropriate to give a smaller weightage for both variables. The lowest weightage of 10 is given to the duration a firm spends in international businesses.

Consistent with previous international entrepreneurship research (Eriksson, Johanson, Majkgard \& Sharma, 1997), the current study will measure international knowledge and experience using the following constructs: (a) the possession of business knowledge (in the areas of cooperative agreements and formations of foreign subsidiaries); (b) the possession of institutional knowledge (knowledge about foreign laws and norms, and foreign languages); (c) the possession of internationalization knowledge (foreign experience in dealing with foreign business partners); and (d) an understanding of perceived costs. These constructs are composed of objective and experiential knowledge which is a central construct in the Uppsala internationalization process model, as it facilitates mobilizing the capital and human resources needed for international expansion.

There is continuous argument regarding the choice of the correct measurement for size. In some studies, the number of employees was used as the measure (Bilkey \& Tesar, 1977; Cavusgil \& Naor, 1987), while some researches have used sales levels of the firm (Hester, 1985; Holden, 1986). In this study, the average sales for the last five years have been used to measure size as they appear to be most relevant in the review of descriptive statistics of this study. Based on the review of research by Calof (1994), researchers prefer to use either sales or number of employees to measure size. But, sales was showing significant findings related to the export behaviour of the firms. Therefore, this study measured size by using the average sales for the past five years.

Normality of this study's variables was established by evaluating the data distributions for skewness and kurtosis. Based on the results of these tests, the histograms for the independent variables have normal distributions. The probability plot charts also show a normal distribution where the points cluster around a straight line. The mean value is equal to zero and the standard deviation more than one which shows a normal distribution of the variables.

IJMS 18 (2), 67-82 (2011) 75 


\section{Statistical Analysis}

The statistical analysis of the research hypothesis was the hierarchical moderated regression. The significance of $R^{2}$ change was used to identify the significance of the model, with and without a moderator. The predictive ability of each independent variable within the block was examined based on the significance level of less than five per cent.

\section{Results}

A total of 300 companies were selected in this research, with a response rate of 27.0 per cent. The respondents in this research were involved in various types of industry. They were divided into two major categories involved in manufacturing, either consumer or industrial products. Companies producing industrial products made up 72.7 per cent whereas the balance of 27.3 per cent were manufacturing consumer products. The majority (46.8 per cent) of the respondents held the position of managing director. Marketing managers consisted of 27.3 per cent, the second highest number of respondents. The average annual sales of the SMEs for the previous five years indicated 49.4 per cent achieving average annual sales of RM6 to 10 million while 28.6 per cent had average annual sales of RM11-15 million.

Table 1.0

Hierarchical Moderated Regression Analysis

Variable Beta $t$-value sig. $\mathrm{R}^{2}$ adjusted $\mathrm{R}^{2} \quad \Delta \mathrm{R}^{2} \quad \Delta \mathrm{F} \Delta \mathrm{F}$ Sig.

Without firm size as a moderator

\begin{tabular}{lllllllll}
\hline $\begin{array}{l}\text { International } \\
\text { knowledge and } \\
\text { experience (IKE) }\end{array}$ & 0.09 & 0.66 & 0.51 & 0.09 & 0.02 & 0.09 & 0.14 & 0.98 \\
\hline Size & 2.53 & 2.49 & 0.02 & & & & & \\
\hline
\end{tabular}

With firm size as a moderator

\begin{tabular}{lllllllll}
\hline $\begin{array}{l}\text { International } \\
\text { knowledge and } \\
\text { experience (IKE) }\end{array}$ & -1.58 & -2.43 & 0.02 & 0.25 & 0.13 & 0.16 & 2.75 & $0.03^{*}$ \\
\hline
\end{tabular}

${ }^{*} p<0.05$

76 IJMS 18 (2), 67-82 (2011) 
Table 1.0 shows the output of the statistical analysis using the hierarchical moderated regression analysis. There is no significant relationship between international knowledge and experience, and internationalization, as shown by the significance level of 0.98 at $p<0.05$. But, when firm size is used as a moderating variable, there is a significant relationship between international knowledge and experience, and internationalization, as shown by the significance level of 0.03 at $p<0.05$. It also indicates that the interactive effect of size is significant at $p<0.05$. The adjusted $R^{2}$ of 13 per cent explains better when relatively compared without the inclusion of firm size where adjusted $R^{2}$ is only two per cent. This explains that firm size moderates the relationship between international knowledge and experience and internationalization at $p<0.05$. The beta value of -1.58 illustrates that the interactive effect of firm size and international knowledge and experience (IKE) on firm internationalization is negative with the presence of firm size as a moderator. This relationship will be explained further in the following section using Figure 2.0.

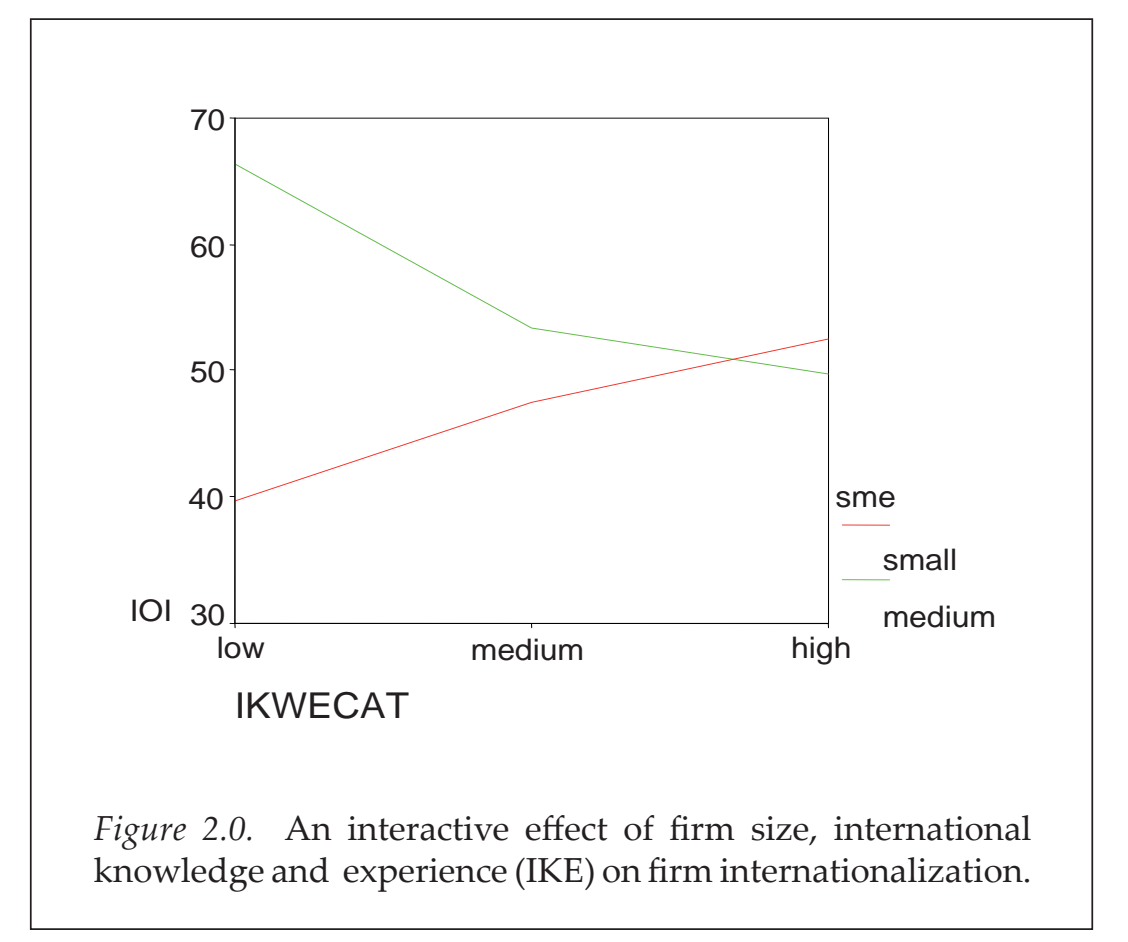

The negative relationship can be further understood through Figure 2.0, which explains graphically the phenomenon of interactive effect of firm size and IKE on firm internationalization. The firm size was conceptualized as a small-sized firm and a medium-sized 
firm to provide a clear distinction between them in the analysis. It is represented by a red and a green line respectively in Figure 2.0. The finding shows that only smaller-sized firms show a positive relationship between IKE and firm internationalization. The finding leads to the logical reasoning why smaller firms usually require IKE to support their internationalization effort. As most SMEs fear the risk of associating with internationalization as they need to deal with unfamiliar culture, volatile foreign exchange market, high market sensitivity, stiffer competition, and strict government regulation, information seeking from experienced firms and building a sound knowledge in international business becomes a crucial learning exploration for SMEs, especially the small ones. Many small firms in Malaysia appear to expose themselves to international trade through active participation in international trade fairs organized by government agencies, and they also seem to capitalize on the many networks of other successful international firms. It is also apparent that among the SMEs with "high" IKE, the small-sized firms appeared to have a higher score of internationalization compared to the medium-sized firms.

On the other hand, medium-sized firms show a negative relationship between IKE and firm internationalization. It is illustrated by a green line in Figure 2.0. When the small-sized firms grow to reach mediumsized level, more IKE leads to less internationalization. We are unable to explain why higher IKE seems to lead to lower internationalization among medium-sized firms. It is possible that for bigger firms (i.e., medium-sized firms), IKE is less important for internationalization. However, we are rather puzzled about the finding that indicates that IKE has a negative influence on internationalization for mediumsized firms. We think this phenomenon needs further investigation.

Since the IOI is measuring $75 \%$ of the SMEs involved in exporting activities which are in their early stage of internationalization, the IKE is very critical for the SMEs for their internationalization. But, when the firms mature and become bigger in size, in this case growing to medium-sized firms, there are other factors that could explain well the relationship with IOI instead of IKE. That triggers further investigation in future research to understand the antecedents of internationalization of medium-sized firms.

\section{Discussion}

There is also a strong relationship between size and internationalization. The findings are consistent with the literature which showed that firm size has some influence on firm internationalization. It is positively and 
significantly correlated with the measure of the team's international selling experience which shows that larger SMEs are more likely to have teams with international selling experience.

A firm can be considered small in two different but related ways; in terms of sheer organizational size or its industry market share. Although size and market share are conceptually different, empirically they are correlated. Firm size has long been considered one of the most significant contingency variables in macro-organizational studies and its relationship with other important constructs such as international knowledge and experience. The dominant logic of this study is further strengthened since small firms need more support in terms of resources, commitment and export skills. Apart from fulfilling this study's objectives and shedding some light on the interactive effect of size, the results may also provide a clue as to why the results of past studies have been mixed. Given the low amount of variance accounted for by firm size, past studies may have had too few observations to produce sufficient variance to reveal statistically significant differences. Perhaps the most important finding is that international knowledge and experience are contributing to the small-sized firms' internationalization. The importance of knowledge and experience in international activities is worth considering since it directly contributes to increasing the value of the firm.

\section{Limitations}

It becomes clear that the research method, particularly the moderate response rate and small sample size, lack of time series data and possible bias from multiple informants, restrict the robustness and generalizability of the conclusions. The geographical region covered by the research is limited to the northern region of West Malaysia only. The SMEs in the manufacturing sector may have shown a different result for the determinants of internationalization in other parts of Malaysia. The response rate was only 27 per cent. The dispatch of the questionnaires through the post could have contributed to the moderate response rate. Although the response rate is acceptable statistically, the research findings could have been more constructive if more responses had been received.

\section{Implications and Future Research}

In spite of these limitations, the findings carry significant potential implications for both SMEs and policy makers based upon the regional and the industry compositions of the sample. Policy makers

IJMS 18 (2), 67-82 (2011) 79 
could work with SMEs in their regions to help determine the unique capabilities and simultaneously examine foreign markets to identify those that might be interested and benefit most from their region's products and services.

The study has attempted to use size as a moderating factor. Admittedly it is still crude and could be improved, but a start has been made. Future research on size and internationalization needs to emphasize on size measurement construction. Is sales volume a good proxy for size? Sometimes sales volume could be very confidential for some SMEs unless it is published in the official document or released to the press.

There is a significant relationship between international knowledge and experience with internationalization when size is used as a moderator. The findings also show that the importance of the size factor is reduced when SMEs grow. A similar impact on internationalization is indicated since the importance of size is reduced when SMEs grow.

Nevertheless, the SMEs in Malaysia have internationalized significantly as shown by the index of internationalization. Almost 60 per cent of the sample scored an index of more than 60. It could be the SMEs in Malaysia and those in Western countries are different in terms of their historical backgrounds. In Malaysia, SMEs can be established based on government support or individual wealth. In Western countries, SMEs have existed for a long time and evolved through major recessions. Therefore, the factors that determine internationalization can vary distinctively.

The study offers additional implications of particular interest to researchers in this field. The contributions of the model used in the current study are that it integrates previous theoretical and empirical knowledge in international businesses and adapts some components to the idiosyncrasies of the SMEs. As a result, this study brings theoretical and empirical rigour to the Malaysian SME literature, which is primarily theoretical and anecdotal.

\section{Conclusion}

The SMEs are the key drivers of the economy in most of the emerging economies. This current study is useful in determining the impact of IKE on internationalization. The government of Malaysia is expected to invest more in the development of SMEs

80 IJMS 18 (2), 67-82 (2011) 
through the Economic Transformation Programme (ETP) and the Government Transformation Programme (GTP). Upon realizing the importance of IKE, the SMEs need to fully utilize the abundance of information through these programmes in leading to success through internationalization.

\section{References}

Abdul Talib, A. N., \& Md Salleh, M. F. (1997). Firm size and export attitudes of Malaysian exporters. Proceedings of $2^{\text {nd }}$ Asian Academy of Management Conference: Towards Management Excellence in the $21^{\text {st }}$ Century Asia (pp. 403-408). Langkawi, Malaysia: Universiti Sains Malaysia.

Abdullah, M. A. (1997). Perception and attitude of small and medium industries' entrepreneurs towards training in Malaysia: A case of Penang. Proceedings of $2^{\text {nd }}$ Asian Academy of Management Conference: Towards Management Excellence in the 21 $1^{\text {st }}$ Century Asia (pp. 238-243). Langkawi, Malaysia; Universiti Sains Malaysia.

Aldrich, H. E., \& Auster, E. (1986). Even dwarfs started small: Liabilities of size and age and their strategic implications. Research in Organization Behavior, 8(1), 165-198.

Bell, J., McNaughton, R., Young, S., \& Crick, D. (2003). Towards an integrative model of firm internationalization. Journal of International Entrepreneurship, 1(1), 339-62.

Bilkey, W. J., \& Tesar, G. (1977). The export behavior of smaller-sized Wisconsin manufacturing firms. Journal of International Business Studies, 8(1), 93-98.

Bonaccorsi, A. (1992). On the relationship between firm size and export intensity. Journal of International Business, 23(Fall), 605635.

Bradley, F. (1999). International marketing strategy (2nd ed.). England: Prentice Hall.

Burpitt, W. J., \& Rondinelli, D. A. (2000). Small firms' motivations for exporting: To earn and learn? Journal of Small Business Management, October, 1-14.

Calof, J. L. (1994). The relationship between firm size and export behavior revisited. Journal of International Business Studies, 25(2), 367-387.

Cavusgil, S. T. (1976). Organizational determinants of firms' export behavior: An empirical analysis (Unpublished doctoral dissertation). University of Wisconsin.

Cavusgil, S. T. (1984). Differences between exporters based on their degree of internationalization. Journal of Business Research, 18(2), 195-208.

IJMS 18 (2), 67-82 (2011) 81 
Cavusgil, S. T., \& Nevin, J. R. (1981). Internal determinants of export marketing behavior: An empirical investigation. Journal of Marketing Research, 23, 114-19.

Cavusgil, S.T., \& Naor, J. (1987). Firm and management characteristics as discriminators of export marketing activity. Journal of Business Research, 15(3), 221-35.

Coviello, N. (2006). The network dynamics of international new ventures. Journal of International Business Studies, 37(5), 713-31.

Eriksson, K., Johanson, J., Majkgard, A., \& Sharma, D. D. (1997). Experiential knowledge and cost in the internationalization process. Journal of International Business Studies, Second quarter.

George, G., Wiklund, J., \& Zahra, S. (2005). Ownership and the internationalization of small firms. Journal of Management, 31, 210-233.

Hashim, M. K. (2000b). SMEs in Malaysia: Past, present and future. Malaysian Management Review, June, 22-30.

Hester, S. (1985). Export trading companies: A marketing vehicle for small textile and apparel firms? Journal of Small Business Management, October, 20-27.

Holden, A. (1986). Small business can market in Europe: Results from a survey of U.S. exporters. Journal of Small Business Management, 24 (1), January, 22-29.

Lubit, R. (2001). Tacit knowledge and knowledge management: The keys to sustainable competitive advantage. Organizational Dynamics, 29(4), 164-178.

Melia, M. R., Boulard, M. M., \& Peinado, L. S. (2007). Entrepreneurial orientation and international commitment. Journal of International Entrepreneurship, 5, 65-83.

Oviatt, B. M., \& McDougall, P. P. (2005). Defining international entrepreneurship and modeling the speed of internationalization. Entrepreneurship Theory and Practice, 29(5), 537-53.

Reuber, A. R., \& Fischer, E. (1997). The influence of the management team's international experience on the internationalization behaviors of SMEs. Journal of International Business Studies, 28, 807-825.

Sullivan, D. (1994). Measuring the degree of internationalization of a firm. Journal of International Business Studies Second quarter, 325-342.

Tesar, G., \& Moini, A. H. (1998). Longitudinal study of exporters and nonexporters: A focus on smaller manufacturing enterprises. International Business Review, 7(3), 291-313.

Zulkifli, N., \& Jamaluddin, M. Y. (2000, Dec). Manufacturing and business strategy practices of the small and medium scale industries in Malaysia. Malaysian Management Review, 11-19.

82 IJMS 18 (2), 67-82 (2011) 